\title{
STEM Moiré Observation of Lattice-Relaxed Germanium Grown on Silicon
}

\author{
Junji Yamanaka', Chiaya Yamamoto ${ }^{2,3}$, Hiroki Nakaie1, Tetsuji Arai', Keisuke Arimoto', \\ Kosuke 0. Hara1, Kiyokazu Nakagawa1
}

${ }^{1}$ Center for Crystal Science and Technology, University of Yamanashi, Kofu, Japan

${ }^{2}$ Center for Creative Technology, University of Yamanashi, Kofu, Japan

${ }^{3}$ Center for Instrumental Analysis, University of Yamanashi, Kofu, Japan

Email: jyamanak@yamanashi.ac.jp

How to cite this paper: Yamanaka, J., Yamamoto, C., Nakaie, H., Arai, T., Arimoto, K., Hara, K.O. and Nakagawa, K. (2017) STEM Moiré Observation of Lattice-Relaxed Germanium Grown on Silicon. Journal of Materials Science and Chemical Engineering, 5, 102-108. http://dx.doi.org/10.4236/msce.2017.51014

Received: November 30, 2016 Accepted: January 13, 2017

Published: January 16, 2017

\begin{abstract}
We deposited Ge films on Si substrates by molecular beam epitaxy (MBE) method. The specimens were annealed at around $750 \mathrm{C}$ using microwaveplasma heating technique which we had reported before. After these processes, we carried out special scanning transmission electron microscopic (STEM) observation. The moiré between the crystal lattices and the scanning lines controlled by STEM was utilized to show lattice-spacing distribution. The results exhibited that we were succeeded in forming lattice-relaxed $\mathrm{Ge}$ thin films. It was also recognized that this STEM moiré technique is very useful to observe lattice-spacing distribution for large area with high resolution.
\end{abstract}

\section{Keywords}

STEM Moiré, Lattice Strain, Ge on Si, Plasma Heating

\section{Introduction}

$\mathrm{Ge}$ is an attracting material for high-speed devices because of its high-carriermobility [1] [2] [3] [4]. A Ge film on Si substrate has many advantages compared with bulk Ge wafer when we think about future industrial application. However, it is not easy to grow low dislocation-density Ge films onto Si because of their $4 \%$ lattice mismatch [5] [6]. In order to reduce dislocation density of $\mathrm{Ge}$ films, post-growth annealing might be the most common method. However, it may cause interdiffusion between the Ge films and the Si substrates because the $\mathrm{Ge}-\mathrm{Si}$ is an isomorphous system [7]. In order to overcome this issue, we applied a new rapid heating technique proposed by our group and succeeded in forming Ge thin films on Si substrates [8] [9] [10].

From the other viewpoint, it is important to study lattice strains or lattice- 
space distributions of semiconductors because they are strongly affected electric properties. Recently other researchers discovered that the moiré fringes between semiconductor lattices and scanning lines produced by STEM could be used to analyze distributions of lattice strains [11]-[17].

In this study we applied this quite new technique to our specimen $(\mathrm{Ge} / \mathrm{Si})$ and it was evaluated that we were succeeded in forming Ge films with no strains all over the specimen.

\section{Experimental Procedure}

\subsection{MBE Growth and Plasma Heating}

We prepared the specimens using same procedure which has been published [10]. Therefore only important part of the Ge film growth and plasma heating will be shown in this paper. Ge films with $300 \mathrm{~nm}$-thick were epitaxially grown onto the $\mathrm{Si}(100)$ substrate by MBE. The substrate temperature was $300 \mathrm{C}$. Then $150 \mathrm{~nm}$-thick $\mathrm{SiO}_{2}$ was deposited onto the $\mathrm{Ge} / \mathrm{Si}$ at $300 \mathrm{C}$ by plasma CVD as a barrier against $\mathrm{W}$ diffusion into the Ge. After that, $100 \mathrm{~nm}$-thick $\mathrm{W}$ was deposited onto the $\mathrm{SiO}_{2} / \mathrm{Ge} / \mathrm{Si}$ at room temperature by RF-sputtering as a heat source of the plasma heating. Then we set the specimen in the microwave-hydrogenplasma heating chamber and heated the specimen up to $700 \mathrm{C}$. It took less than 2 seconds that the temperature reached to $700 \mathrm{C}$ from the room temperature. Just after the specimen-temperature reached to $700 \mathrm{C}$, we shut down the plasm power and it took about 10 seconds that the specimen-temperature decreased to room temperature.

\subsection{STEM Moiré Observation}

We deposited protection layers onto the annealed specimen to avoid damages caused by focused ion beam (FIB). First, we deposited an amorphous carbon onto the $\mathrm{W} / \mathrm{SiO}_{2} / \mathrm{Ge} / \mathrm{Si}$ by simple vacuum evaporation. Second, Pt-Pd alloy was deposited onto the $\mathrm{C} / \mathrm{W} / \mathrm{SiO}_{2} / \mathrm{Ge} / \mathrm{Si}$ by magnetron sputtering. Then the specimen was set into the FIB and $\mathrm{W}$ was deposited onto the $\mathrm{Pt}-\mathrm{Pd} / \mathrm{C} / \mathrm{W} / \mathrm{SiO}_{2} / \mathrm{Ge} / \mathrm{Si}$ by ion-assisted chemical deposition in the FIB chamber. After preparing these protection layers, the specimen was fabricated by FIB (Hitachi FB-2100A). Then we checked the microstructure of the specimen using conventional TEM and STEM methods. After that, we set up the STEM condition carefully and took high-resolution STEM images and STEM moiré with the acceleration voltage of $200 \mathrm{kV}$. We mainly used field-emission type STEM (FEI, Tecnai Osiris). The STEM is not a Cs corrected microscope so it is almost impossible to take atomic-resolution STEM images but it has enough potential to take crystal-latticeresolution STEM images. Therefore this STEM is suitable for our purpose to take STEM moiré fringes.

Figure 1 is a schematic illustration of the STEM moiré pattern. STEM moiré is a kind of fringe between the crystal-lattice spacing and the electron-beam scanning lines. In this study, we focused on the Ge and Si (111) planes and we set the scanning-line period to $632 \mathrm{pm}$. 


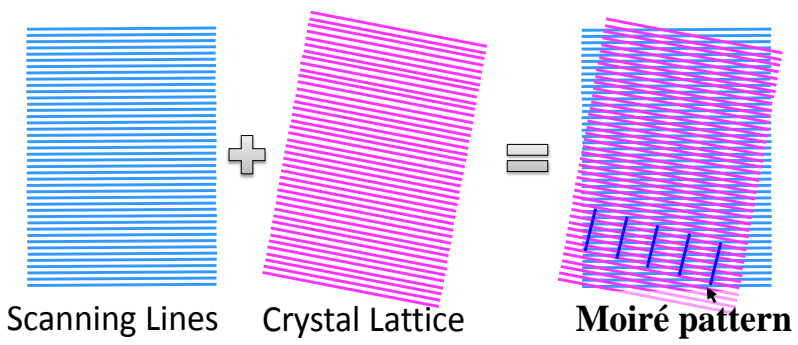

Figure 1. An schematic illustration of the STEM moiré pattern, interaction between the STEM scanning lines and the crystal lattices.

\section{Results and Discussion}

Figure 2 and Figure 3 are results of overall STEM observations. The bright field STEM image (Figure 2) shows that the dislocation density of this Ge film is low even though there are $4 \%$ lattice mismatch between the Si substrate. The Si there and the high-angle-annular-dark-filed (HAADF) STEM image (Figure 3) suggests that the Ge film is compositionally uniform.

The bright field STEM image (Figure 2) shows that the dislocation density of this $\mathrm{Ge}$ film is low even though there are $4 \%$ lattice mismatch between the $\mathrm{Si}$ substrate. The Si there and the high-angle-annular-dark-filed (HAADF) STEM image (Figure 3) suggests that the Ge film is compositionally uniform. Figure 4 is a high-resolution HAADF-STEM image of the Ge part which is located just on the Si substrate. This high-resolution image suggests that the Ge lattice is not strained even on the Si substrate. However, high-resolution TEM and STEM images can not cover micrometer order wide area in general. This is one of the weak point of TEM and STEM.

In order to overcome this weak point and to analyze the lattice spacing distribution, we carried out a quite new STEM technique proposed by other researchers [11]-[17]. Figure 5 is a schematic illustration how to take a STEM moiré pattern. In this work, we tried to take two different STEM moiré patterns simultaneously: 1) moiré pattern between Ge (111) planes and STEM scanning lines and 2) moiré pattern between Si (111) planes and STEM scanning lines. Therefore, we set the STEM scan direction almost parallel to but not exactly parallel to (111) planes. Figures 6-8 are STEM moiré patterns taken from the annealed specimen. Figure 6 is the original data which we did not do any contrast/ brightness modification. In the case of Figure $\mathbf{7}$ and Figure 8, the image contrast was adjusted for $\mathrm{Si}$ area and Ge area, respectively. These data include two important information. First, the directions and spacing or the STEM moiré patterns in Ge area and $\mathrm{Si}$ area are drastically changed across the Ge/Si interface. This is because of the $4 \%$ lattice mismatch between Ge and Si. Second, the STEM moiré pattern in Ge area is not bending at all. This means that the Ge (111) lattice planes keep same direction and same spacing at least inside the observed are. The observed are was submicron squared, so it is assumed that the Ge film is not strained all over the specimen. 


\section{W}

$\mathrm{SiO}_{2}$

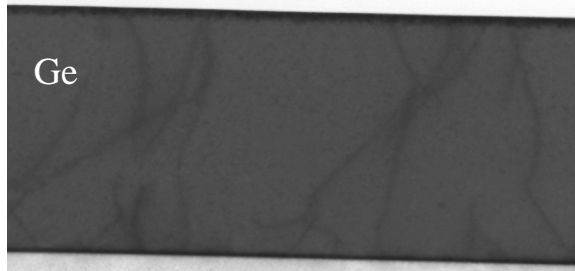

Si

Figure 2. Low magnification STEM bright field image. There exist some dislocations but the dislocation density is not so high.

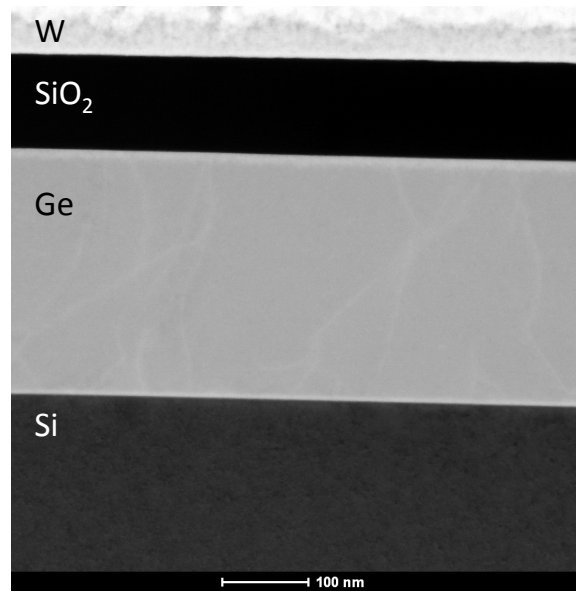

Figure 3. Low magnification STEM HAADF image. It is clear that the Ge film is compositionally uniform.

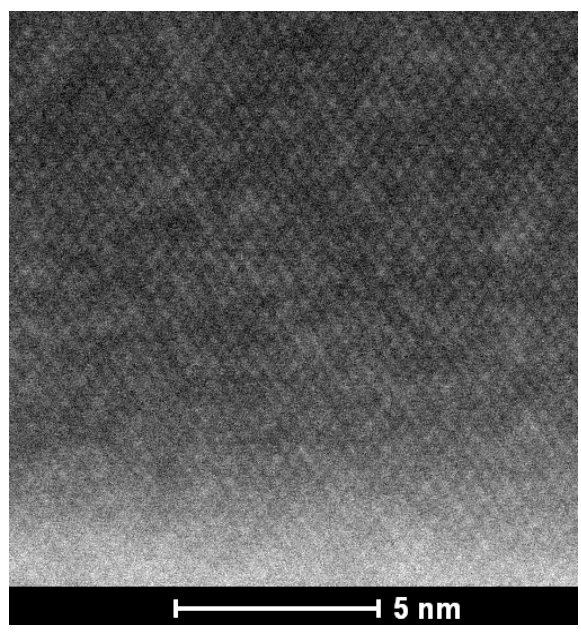

Figure 4. A high-resolution HAADF-STEM image of the Ge part. 


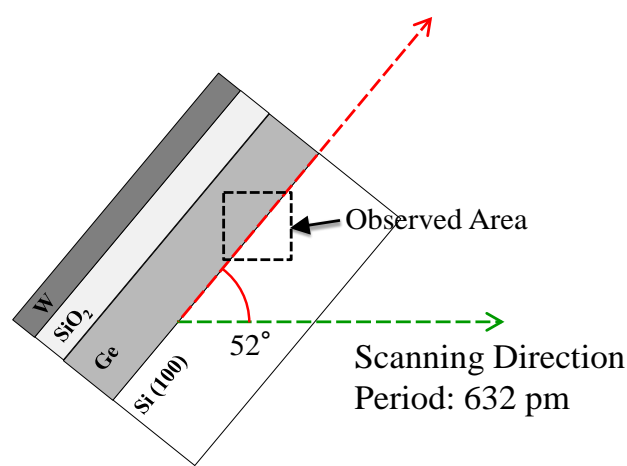

Figure 5. A schematic illustration how to take a STEM moiré pattern. The STEM scan direction is almost parallel to (111) planes but it is not exactly parallel to them.

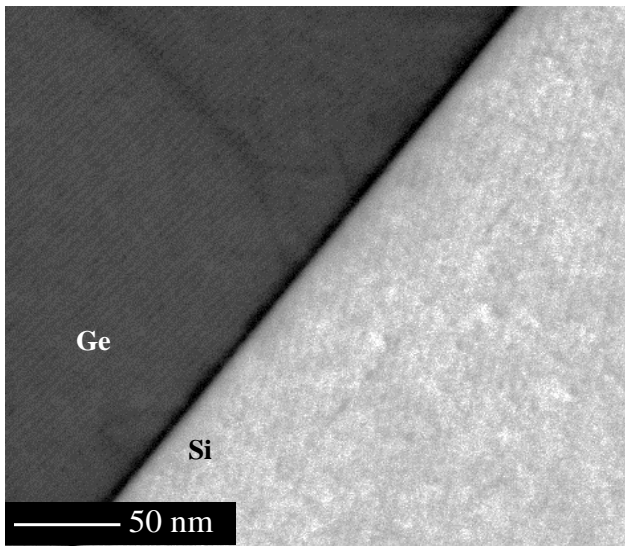

Figure 6. A STEM moiré patterns pattern taken from the annealed specimen. This micrograph is the original one which we did not do any contrast/brightness modification. In Figure 7 and Figure 8, modified micrographs are shown.

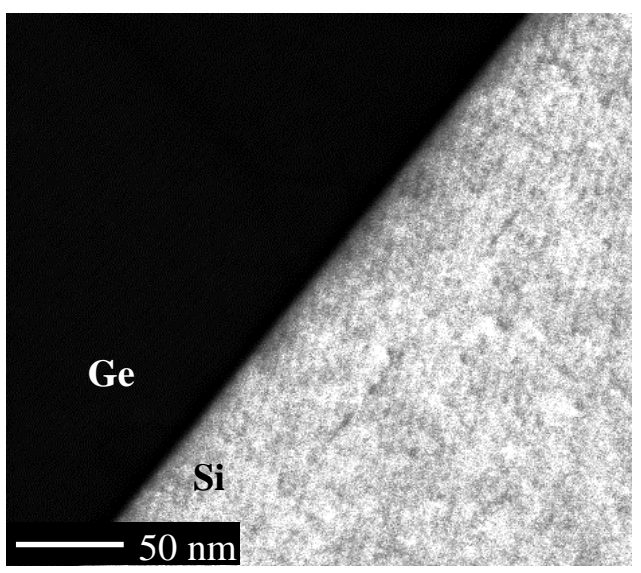

Figure 7. A STEM moiré patterns pattern taken from the annealed specimen. Contrast and brightness were adjusted for $\mathrm{Si}$ are. The original micrograph is shown in Figure 6. The other modified micrograph is shown in Figure 8. 


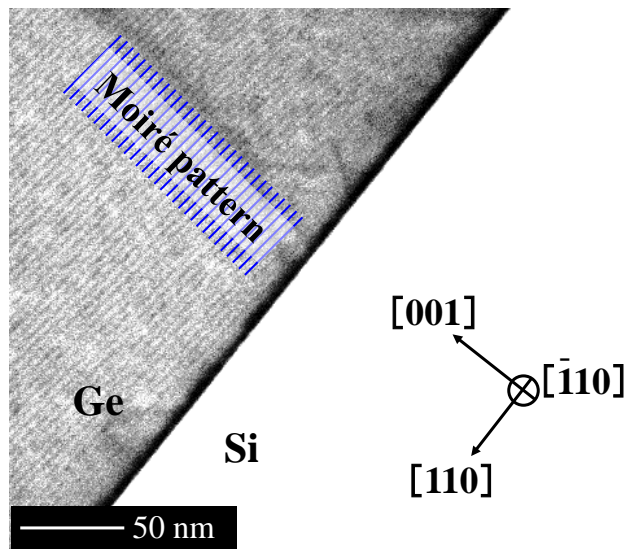

Figure 8. A STEM moiré patterns pattern taken from the annealed specimen. Contrast and brightness were adjusted for $\mathrm{Ge}$ are. The original micrograph is shown in Figure 6. The other modified micrograph is shown in Figure 7.

\section{Summary}

In this study, we produced a low-dislocation-density Ge thin film onto Si substrate by MBE followed by microwave-hydrogen plasma heating. We precisely analyze the lattice-space distribution by using STEM moiré pattern and it is proved that the Ge film is not strained. This means that we are succeeded in forming a completely relaxed uniform Ge thin film on the $\mathrm{Si}$, and the film has good crystallinity. It was also shown that the STEM moiré pattern is very useful to investigate the lattice-space distributions.

\section{Acknowledgements}

The authors thank Dr. Yukihito Kondo and Dr. Noriaki Endo of JEOL Ltd. for useful suggestions. We also thank Dr. Kazuo Ishizuka, Dr. Akimitsu Ishizuka, and Dr. Hirofumi Matsuhata of HREM Research Inc. for their kind comments.

\section{References}

[1] Lee, C.H., Nishimura, T., Tabata, T., Wang, S.K., Nagashio, K., Kita, K. and Toriumi, A. (2010) Ge MOSFETs Performance: Impact of Ge Interface Passivation. 2010 IEEE International Electron Devices Meeting (IEDM), 18-1. https://doi.org/10.1109/iedm.2010.5703384

[2] Maeda, T., Ikeda, K., Nakaharai, S., Tezuka, T., Sugiyama, N., Moriyama, Y. and Takagi, S. (2006) Thin-Body Ge-on-Insulator p-Channel MOSFETs with Pt Germanide Metal Source/Drain. Thin Solid Films, 508, 346-350. https://doi.org/10.1016/j.tsf.2005.07.339

[3] Kamata, Y. (2008) High-k/Ge MOSFETs for Future Nanoelectronics. Materials Today, 11, 30-38. https://doi.org/10.1016/S1369-7021(07)70350-4

[4] Lee, M.L., Leitz, C.W., Cheng, Z., Antoniadis, D.A. and Fitzgerald, E.A. (2002) Strained Ge Channel p-Type Metal-Oxide-Semiconductor Field-Effect Transistors Grown on Siâ â xGex/Sivirtual Substrates.

[5] Luan, H.C., Lim, D.R., Lee, K.K., Chen, K.M., Sandland, J.G., Wada, K. and Kimerl- 
ing, L.C. (1999) High-Quality Ge Epilayers on Si with Low Threading-Dislocation Densities. Applied Physics Letters, 75, 2909-2911. https://doi.org/10.1063/1.125187

[6] Currie, M.T., Samavedam, S.B., Langdo, T.A., Leitz, C.W. and Fitzgerald, E.A. (1998) Controlling Threading Dislocation Densities in Ge on Si Using Graded SiGe Layers and Chemical-Mechanical Polishing. Applied Physics Letters, 72, 1718-1720. https://doi.org/10.1063/1.121162

[7] Massalski, T.B., Okamoto, H., Subramanian, P.R. and Kacprzak, L. (1990) Binary Alloy Phase Diagrams. 2nd Edition, ASM International.

[8] Arai, T., Nakaie, H., Kamimura, K., Nakamura, H., Ariizumi, S., Ashizawa, S. and Takamatsu, T. (2016) Selective Heating of Transition Metal Using Hydrogen Plasma and Its Application to Formation of Nickel Silicide Electrodes for Silicon Ultralarge-Scale Integration Devices. Journal of Materials Science and Chemical Engineering, 4, 29. https://doi.org/10.4236/msce.2016.41006

[9] Arai, T., Kamimura, K., Yamamoto, C., Shirakura, M., Arimoto, K., Yamanaka, J., Nakagawa, K., Takamatsu, T., Ogino, M., Tachioka, M. and Nakazawa, H. (2017) Ohmic Contact Formation for $\mathrm{n}+4 \mathrm{H}-\mathrm{SiC}$ Substrate by Selective Heating Method Using Hydrogen Radical Irradiation. Journal of Materials Science and Chemical Engineering, 5, 35-41. https://doi.org/10.4236/msce.2017.51005

[10] Nakaie, H., Arai, T., Yamamoto, C., Arimoto, K., Yamanaka, J., Nakagawa, K. and Takamatsu, T. Reduction of dislocation Densities of Ge Layers Grown on Sisubstrates by Using Microwave Plasma Heating and Fabrication of High Hole Mobility MOSFETs on Ge Layers. Journal of Materials Science and Chemical Engineering. (To Be Published)

[11] Su, D. and Zhu, Y. (2010) Scanning Moiré Fringe Imaging by Scanning Transmission Electron Microscopy. Ultramicroscopy, 110, 229-233. https://doi.org/10.1016/j.ultramic.2009.11.015

[12] Kim, S., Lee, S., Oshima, Y., Kondo, Y., Okunishi, E., Endo, N., Jung, J., Byun, G., Lee, S. and Lee, K. (2013) Scanning Moiré Fringe Imaging for Quantitative Strain Mapping in Semiconductor Devices. Applied Physics Letters, 102, Article ID: 161604. https://doi.org/10.1063/1.4803087

[13] Kim, S., Kim, J.J., Jung, Y., Lee, K., Byun, G., Hwang, K.H., Lee, S. and Lee, K. (2013) Reliable Strain Measurement in Transistor Arrays by Robust Scanning Transmission Electron Microscopy. AIP Advances, 3, Article ID: 092110. https://doi.org/10.1063/1.4821278

[14] Kim, S., Kondo, Y., Lee, K., Byun, G., Kim, J.J., Lee, S. and Lee, K. (2013) Quantitative Measurement of Strain Field in Strained-Channel-Transistor Arrays by Scanning Moiré Fringe Imaging. Appl. Phys. Lett., 103, Article ID: 033523. https://doi.org/10.1063/1.4816286

[15] Kim, S., Lee, S., Oshima, Y., Kondo, Y., Lee, H., Lee, K., Kim, S., Lee, S., Oshima, Y., Kondo, Y., Lee, H. and Lee, K. (2014).

[16] Kim, S., Lee, S., Kondo, Y., Lee, K., Byun, G., Lee, S. and Lee, K. (2013) Journal of Applied Physics, 114, Article ID: 053518. https://doi.org/10.1063/1.4817729

[17] Kondo, Y. and Endo, N. (2014) Strain Analysis Using STEM Moiré Method. Kenbikyo, 49, 226. (In Japanese) 
Submit or recommend next manuscript to SCIRP and we will provide best service for you:

Accepting pre-submission inquiries through Email, Facebook, LinkedIn, Twitter, etc. A wide selection of journals (inclusive of 9 subjects, more than 200 journals)

Providing 24-hour high-quality service

User-friendly online submission system

Fair and swift peer-review system

Efficient typesetting and proofreading procedure

Display of the result of downloads and visits, as well as the number of cited articles Maximum dissemination of your research work

Submit your manuscript at: http://papersubmission.scirp.org/

Or contact msce@scirp.org 